\title{
The effects of missed doses of amlodipine and losartan on blood pressure in older hypertensive patients
}

\author{
Citation for published version (APA): \\ de Leeuw, P. W., Fagard, R., \& Kroon, A. A. (2017). The effects of missed doses of amlodipine and \\ losartan on blood pressure in older hypertensive patients. Hypertension Research, 40(6), 568-572. \\ https://doi.org/10.1038/hr.2016.190
}

\section{Document status and date: \\ Published: 01/06/2017}

DOI:

10.1038/hr.2016.190

\section{Document Version:}

Publisher's PDF, also known as Version of record

\section{Document license:}

Taverne

\section{Please check the document version of this publication:}

- A submitted manuscript is the version of the article upon submission and before peer-review. There can be important differences between the submitted version and the official published version of record.

People interested in the research are advised to contact the author for the final version of the publication, or visit the DOI to the publisher's website.

- The final author version and the galley proof are versions of the publication after peer review.

- The final published version features the final layout of the paper including the volume, issue and page numbers.

Link to publication

\footnotetext{
General rights rights.

- You may freely distribute the URL identifying the publication in the public portal. please follow below link for the End User Agreement:

www.umlib.nl/taverne-license

Take down policy

If you believe that this document breaches copyright please contact us at:

repository@maastrichtuniversity.nl

providing details and we will investigate your claim.
}

Copyright and moral rights for the publications made accessible in the public portal are retained by the authors and/or other copyright owners and it is a condition of accessing publications that users recognise and abide by the legal requirements associated with these

- Users may download and print one copy of any publication from the public portal for the purpose of private study or research.

- You may not further distribute the material or use it for any profit-making activity or commercial gain

If the publication is distributed under the terms of Article 25fa of the Dutch Copyright Act, indicated by the "Taverne" license above, 


\title{
The effects of missed doses of amlodipine and losartan on blood pressure in older hypertensive patients
}

\begin{abstract}
Peter W de Leeuw ${ }^{1,2}$, Robert Fagard ${ }^{3}$ and Abraham A Kroon ${ }^{1}$
This randomized, double-blind, parallel-group, multicenter study compared the efficacy of amlodipine and losartan in an older hypertensive population, focusing on therapeutic coverage in the case of missed doses. Following a 4-week, single-blind, placebo washout period, 211 patients were randomly assigned to receive either $5 \mathrm{mg}$ of amlodipine once daily or $50 \mathrm{mg}$ of losartan once daily. Doses were doubled after 6 weeks of treatment if the diastolic blood pressure exceeded $90 \mathrm{~mm} \mathrm{Hg}$. After the 12-week treatment period, patients received the placebo for 2 days (drug holiday) to simulate two missed doses of antihypertensive medication. Twenty-four-hour ambulatory blood pressure monitoring was conducted at the end of the placebo washout period (baseline), upon completion of the 12-week treatment period (steady state), and after the 2-day drug holiday. Amlodipine was more effective than losartan in reducing patients' 24-h ambulatory blood pressure at the steady-state sampling time. The increases in 24-h blood pressure during the drug holiday averaged $6 \pm 2 / 2 \pm 1 \mathrm{~mm} \mathrm{Hg}(P<0.0001)$ in the amlodipine group and $3 \pm 2 / 2 \pm 1 \mathrm{~mm} \mathrm{Hg}(P<0.0001)$ in the losartan group. The rise in systolic pressure was greater in patients on amlodipine than in those on losartan $(P<0.0001)$. For diastolic pressure, the changes did not differ. Owing to the lower pressure during treatment, patients in the amlodipine group remained at a significantly lower blood pressure level after the 2-day drug holiday. Amlodipine was more effective than losartan in lowering blood pressure and in maintaining blood pressure control after two missed doses, and the difference was most significant for systolic blood pressure.
\end{abstract}

Hypertension Research (2017) 40, 568-572; doi:10.1038/hr.2016.190; published online 19 January 2017

Keywords: amlodipine; drug holiday; losartan; therapeutic coverage

\section{INTRODUCTION}

As hypertension is an asymptomatic condition, it is often difficult for patients with this condition to perfectly adhere to the prescribed regimen and not miss doses. For instance, in a large group of hypertensive patients, Vrijens et al. ${ }^{1}$ found that almost $95 \%$ of the patients missed a single dose at least once a year. Of all missed doses, $57 \%$ were omissions of 1 or 2 consecutive days. Missed doses are not always intentional because sometimes a patient does not have the pills at hand or simply forgets to take the medication. If we accept this as a fact of life, it becomes important with a once-a-day dosing regimen that antihypertensive drugs exert their effect for a somewhat longer period than $24 \mathrm{~h}$. This longer effect is particularly important when one wants to avoid a loss of morning hypertension control., ${ }^{2,3}$ Although several studies have assessed the efficacy of antihypertensive agents after missed doses, the mean age of the patients in these studies was 50-60 years, and none focused specifically on older people. ${ }^{4}$ This omission is unfortunate because people in this age group are particularly susceptible to a rapid loss of blood pressure control that could be detrimental. There is no evidence that the degree of protection against cardiovascular events by any of the major antihypertensive drug classes is dependent on age, ${ }^{5}$ and all blood pressure lowering drugs can thus be prescribed for older patients. This study was undertaken to compare the effect of the withdrawal of two frequently prescribed antihypertensive drugs, amlodipine and losartan, on the blood pressure profile in a group of patients 65 years or older. The reason to choose those particular drugs was that they both can be administered on a once-daily basis, and both are known to maintain some therapeutic coverage during drug holidays. We hypothesized that, based on the longer elimination half-life of the calcium channel blocker amlodipine compared with that of the angiotensin II receptor type 1 blocker losartan, the former would lower blood pressure for a longer time after withdrawal.

\section{METHODS \\ Patient population \\ Patients 65 years or older with (1) newly diagnosed or known essential hypertension, (2) an office diastolic blood pressure (DBP) $>95 \mathrm{~mm} \mathrm{Hg}$ and $\leqslant 115 \mathrm{~mm} \mathrm{Hg}$ and systolic blood pressure (SBP) >140 mm Hg and $<200 \mathrm{~mm} \mathrm{Hg}$ on at least two occasions and (3) an ambulatory daytime DBP $>85 \mathrm{~mm} \mathrm{Hg}$ off antihypertensive drugs were eligible for randomization. The}

${ }^{1}$ Department of Internal Medicine, Maastricht University Medical Center and Cardiovascular Research Institute Maastricht, Maastricht, The Netherlands; ${ }^{2}$ Department of Medicine, Zuyderland Medisch Centrum, Sittard, The Netherlands and ${ }^{3}$ Hypertension Unit, Leuven University, Leuven, Belgium

Correspondence: Professor PW de Leeuw, Department of Internal Medicine, Maastricht University Medical Center and Cardiovascular Research Institute Maastricht, PO Box 5800, 6202 AZ Maastricht, The Netherlands.

E-mail: p.deleeuw@maastrichtuniversity.nl

Received 27 October 2016; revised 10 November 2016; accepted 24 November 2016; published online 19 January 2017 
main exclusion criteria were major cardiovascular events or procedures within a 3-month period, heart failure (classes II-IV), significant liver disease (aspartateamino transferase or alanine-amino transferase $>3$ times upper normal values) or renal disease (estimated estimated glomerular filtration rate $<60 \mathrm{ml} \mathrm{min}^{-1}$ per $1.73 \mathrm{~m}^{2}$ ), body mass index $>30 \mathrm{~kg} \mathrm{~m}^{-2}$, conditions that may decrease the likelihood of the patient being able to complete the trial, and the need for other blood pressure lowering medications.

\section{Study design and treatment regimen}

This study was a 12-week, randomized, double-blind, double dummy, parallel-group study conducted at 23 sites in seven countries. After a 4-week, single-blind, placebo washout period, patients were randomly assigned to receive either $5 \mathrm{mg}$ of amlodipine once daily or $50 \mathrm{mg}$ of losartan once daily for the first 6 weeks of treatment. If a patient's sitting office DBP exceeded $90 \mathrm{~mm} \mathrm{Hg}$ after 6 weeks of treatment, the dose of study medication was increased to $10 \mathrm{mg}$ amlodipine once daily or $100 \mathrm{mg}$ losartan once daily for the second half of the study. After completing the 12-week treatment period, patients received single-blind placebo medication for 2 days to simulate two missed doses of antihypertensive medication (drug holiday). We did not want to extend the drug holiday any longer because missing medication for 2 days is a realistic phenomenon and because we could not be sure that withholding medication for $>2$ days would not cause problems for the patients in this experimental situation.

\section{Procedures}

Each patient underwent 24-h ambulatory blood pressure monitoring (ABPM) using the validated Spacelabs' 90207 equipment (Spacelabs Healthcare Inc., Issaquah, WA, USA) at the end of the 4-week placebo period, at the end of the 12 -week treatment period (steady state), and at the end of the 2-day drug holiday ( $48 \mathrm{~h}$ after the last dose). During ABPM, the patient's blood pressure was measured every $15 \mathrm{~min}$ from 0600 to 2200 hours and every $30 \mathrm{~min}$ from 2200 to 0600 hours. ABPM data were accepted only when $>80 \%$ of the measurements were available and when $<2$ consecutive hours of measurements were missing. Mean ambulatory blood pressure values were calculated for the daytime (0800-2200 hours), the nighttime (0000-0600 hours) and the entire 24-h period; the transition periods from 0600 to 0800 hours and from 2200 to 0000 hours were skipped for the calculation of the daytime and nighttime mean BP. The early morning blood pressure surge was calculated as the difference between blood pressure during the morning period and the preawakening blood pressure. The decrease of $\mathrm{BP}$ at night was indicated by the 'dipper status'. A patient was considered to be a 'dipper' when the average nighttime $\mathrm{BP}$ was $\geqslant 10 \%$ less than the daytime $\mathrm{BP}$.

Table 1 Patient demographics

\begin{tabular}{lcc}
\hline Characteristic & Amlodipine & Losartan \\
\hline Number of patients & 106 & 105 \\
Male/female & $49 / 57$ & $41 / 64$ \\
& & \\
Age (years) & 94 & 82 \\
$65-74$ & 11 & 21 \\
$75-84$ & 1 & 2 \\
$\geqslant 85$ & 70 & 71 \\
Mean age (years) & $65-87$ & $65-95$ \\
Range & & \\
& 13 & 12 \\
Medical history & $0-50$ & $0-54$ \\
History of hypertension (years) & 7 & 4 \\
$\quad$ Range & 9 & 7 \\
Cerebrovascular disease (\%) & 11 & 5 \\
Peripheral vascular disease (\%) & $27.0 \pm 1.5$ & $26.7 \pm 1.5$ \\
Ischemic heart disease (\%) & & \\
Body mass index (kg m ${ }^{-2}$ ) ( \pm s.d.) & & \\
\hline
\end{tabular}

Sitting office blood pressure measurements at trough (that is, $24 \mathrm{~h}$ after the last dose during treatment and $48 \mathrm{~h}$ after the last dose at the end of the trial) were recorded at each study visit using a conventional mercury sphygmomanometer. The mean of two measurements was taken in the same arm using the appropriate cuff size after the patient had been sitting down quietly for $5 \mathrm{~min}$. Measurements were repeated $2 \mathrm{~min}$ later in the same position.

\section{Statistical analysis}

The analyses were performed using an intention-to-treat approach. The primary efficacy endpoint was the mean change in systolic and diastolic 24-h ABPM values between the end of treatment and the end of the drug holiday. Pairwise comparisons of treatment differences with respect to 24-h ABPM data were evaluated using an analysis of variance with fixed treatment and center effects. As the treatment-by-center interaction was not significant, it was not included in the model. The analysis of variance analyses were also performed for the mean daytime and nighttime ABPM measurements and the mean office sitting blood pressure. Changes in the percent dip in blood pressure at nighttime were analyzed with the Cochran-Mantel-Haenszel test stratified by center. All statistical tests of significance were performed as two-sided tests.

Results are expressed as the means and s.d. unless indicated otherwise. Test statistics comparing treatment groups were considered statistically significant if $P<0.05$ using two-sided tests.

This study was conducted in full compliance with the Declaration of Helsinki, including written informed consent and per local laws and regulations relevant to the conduct of clinical research within the participating countries. Ethical approval was obtained from all participating centers.

\section{RESULTS}

\section{Patient characteristics}

Of the 211 patients treated, 106 received amlodipine and 105 received losartan. The demographic characteristics of the two treatment groups were similar with respect to the mean age and age distribution, medical history, and body mass index (Table 1). Except for two black subjects in the losartan group, all patients were Caucasian. There were proportionally more women in the losartan group (61\%) than in the amlodipine group (54\%). In the amlodipine group, $62 \%$ of the subjects had been previously treated for hypertension, whereas in the losartan group, $56 \%$ subjects were previously treated. The main antihypertensive drug classes in both groups were beta-blockers and diuretics.

Five patients in the amlodipine group were withdrawn from the study prematurely: three for adverse events, one for loss to follow-up and one for other reasons. In the losartan group, six patients discontinued the study before completion: one for adverse events, one for loss to follow-up and four for other reasons.

\section{Dose of study medication}

After 6 weeks of treatment, $46 \%$ of the amlodipine patients and $60 \%$ of the losartan patients had their doses doubled to 10 and $100 \mathrm{mg}$, respectively. The median final dose for the amlodipine group was $7 \mathrm{mg}$, and it was $80 \mathrm{mg}$ daily for the losartan group.

\section{Efficacy evaluation}

Failure to obtain reliable (that is, $80 \%$ or more capture) ABPM data occurred in three patients of the amlodipine group and one patient of the losartan group. The 24-h ABPM results for the remainder of the patients are presented in Figure 1. Amlodipine reduced 24-h SBP from $155 \pm 18$ to $136 \pm 16 \mathrm{~mm} \mathrm{Hg}$ and DBP from $92 \pm 8$ to $80 \pm 8 \mathrm{~mm} \mathrm{Hg}$ $(P<0.0001$ for both). Losartan reduced SBP from $156 \pm 14$ to $144 \pm 18 \mathrm{~mm} \mathrm{Hg}$ and DBP from $92 \pm 8$ to $83 \pm 11 \mathrm{~mm} \mathrm{Hg}(P<0.0001$ for both). Following the cessation of therapy, SBP rose again to $142+16 \mathrm{~mm} \mathrm{Hg}$ in the amlodipine group and to $147 \pm 17 \mathrm{~mm} \mathrm{Hg}$ in 

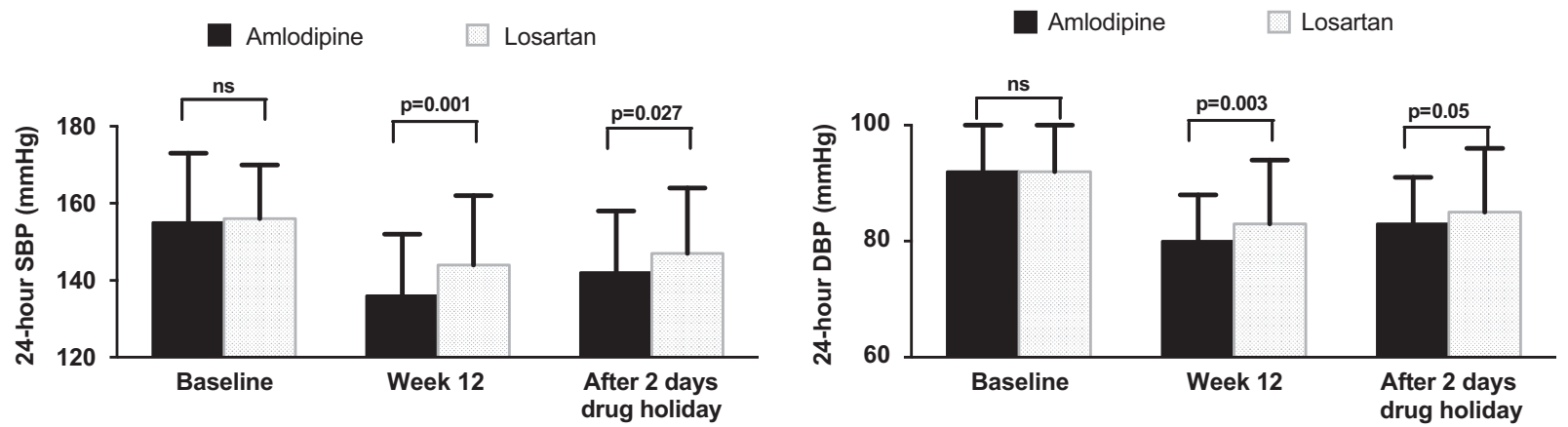

Figure 1 The effect of amlodipine and losartan on 24-h ambulatory blood pressure monitoring (ABPM) during treatment and after two missed doses.

Table 2 Mean daytime and nighttime ambulatory blood pressure $(\mathrm{mm} \mathrm{Hg})$

\begin{tabular}{|c|c|c|c|c|c|c|}
\hline \multirow[b]{2}{*}{ 24-h ABPM } & \multicolumn{3}{|c|}{ Amlodipine } & \multicolumn{3}{|c|}{ Losartan } \\
\hline & $\mathrm{N}$ & Mean & s.d. & $\mathrm{N}$ & Mean & s.d. \\
\hline \multicolumn{7}{|l|}{ Baseline } \\
\hline Daytime SBP & 103 & 158 & 18 & 104 & 158 & 14 \\
\hline Nighttime SBP & 102 & 142 & 21 & 104 & 146 & 17 \\
\hline Dipper status $(\%)^{a}$ & 102 & 46 & - & 104 & 38 & - \\
\hline Daytime DBP & 103 & 94 & 8 & 104 & 94 & 8 \\
\hline Nighttime DBP & 102 & 81 & 11 & 104 & 82 & 10 \\
\hline Dipper status $(\%)^{\mathrm{a}}$ & 102 & 70 & - & 104 & 61 & - \\
\hline \multicolumn{7}{|l|}{ Steady state } \\
\hline Daytime SBP & 97 & $139^{\dagger \dagger \dagger}$ & 17 & 93 & 146 & 19 \\
\hline Nighttime SBP & 97 & $126^{\dagger \dagger \dagger}$ & 17 & 93 & 135 & 18 \\
\hline Dipper status (\%) & 97 & 44 & - & 93 & 39 & - \\
\hline Daytime DBP & 97 & $82^{\dagger \dagger}$ & 9 & 93 & 85 & 11 \\
\hline Nighttime DBP & 97 & $72^{\dagger}$ & 8 & 93 & 76 & 14 \\
\hline Dipper status $(\%)^{a}$ & 97 & 65 & - & 93 & 59 & - \\
\hline \multicolumn{7}{|l|}{ Drug holiday } \\
\hline Daytime SBP & 100 & $145^{\dagger}$ & 16 & 97 & 149 & 17 \\
\hline Nighttime SBP & 98 & $131^{\dagger}$ & 18 & 97 & 137 & 17 \\
\hline Dipper status (\%) ${ }^{\mathrm{a}}$ & 98 & 48 & - & 97 & 40 & - \\
\hline Daytime DBP & 100 & 85 & 8 & 97 & 88 & 11 \\
\hline Nighttime DBP & 98 & $73^{\dagger}$ & 8 & 97 & 76 & 10 \\
\hline Dipper status $(\%)^{\mathrm{a}}$ & 98 & 70 & - & 97 & 61 & - \\
\hline
\end{tabular}

Abbreviations: ABPM, ambulatory blood pressure monitoring; DBP, diastolic blood pressure; $\mathrm{SBP}$, systolic blood pressure.

Between-group comparison: ${ }^{\dagger} P<0.05 ;{ }^{\dagger \dagger} P<0.01 ;{ }^{\dagger \dagger} P<0.001$.

aDipper status: $\%$ of patients with an average fall in nighttime blood pressure of $\geqslant 10 \%$ below the mean daytime blood pressure.

the losartan group $(P<0.01$ for both). For DBP, these figures were $83 \pm 8$ and $85 \pm 11 \mathrm{~mm} \mathrm{Hg}$, respectively $(P<0.05$ for both $)$.

Although similar at baseline, both SBP and DBP were significantly lower on amlodipine compared with losartan at the end of the 12-week treatment period, as well as after two missed doses. When broken down by daytime and nighttime values, a similar pattern was observed with the exception of daytime DBP during the drug holiday, which did not differ between the groups (Table 2).

Figure 2 depicts the 24-h patterns of blood pressure during the three study periods in both groups. The graphs confirm that over the entire 24-h period, systolic pressure increased more after stopping amlodipine than after the discontinuation of losartan, whereas the diastolic pressure rose to the same extent. The primary outcome measure, that is, the numerical increases in 24-h blood pressure during the drug holiday, averaged $6 \pm 2 / 2 \pm 1 \mathrm{~mm} \mathrm{Hg}(P<0.0001)$ in the amlodipine group and $3 \pm 2 / 2 \pm 1 \mathrm{~mm} \mathrm{Hg}(P<0.0001)$ in the losartan group. The rise in SBP was significantly greater in patients on amlodipine than in those on losartan $(P<0.0001)$. For DBP, the changes did not differ between the two groups. Despite the incremental increase in blood pressure during the drug holiday, both SBP and DBP remained significantly lower compared with baseline in both groups. When the effects of the two drugs were compared, the reductions in systolic pressure at the end of the drug holiday were still significantly greater with amlodipine than with losartan $(P<0.01)$, but there was no such difference with respect to DBP.

No changes were observed in dipper status nor in the magnitude of the morning surge during treatment or during the drug holiday. Morning surges in blood pressure at baseline did not differ between the amlodipine and losartan groups. There were no differences between the treatment groups at the end of the 12-week treatment period or at the end of the missed doses.

The mean office blood pressure for patients on amlodipine decreased from $168 \pm 13 / 101 \pm 6 \mathrm{~mm} \mathrm{Hg}$ to $144 \pm 17 / 85 \pm 8 \mathrm{~mm} \mathrm{Hg}$ at steady state and to $148 \pm 15 / 87 \pm 9 \mathrm{~mm} \mathrm{Hg}$ after the drug holiday $(P<0.001$ for both) vs. a decrease for patients on losartan from $168 \pm 12 / 101 \pm 6 \mathrm{~mm} \mathrm{Hg}$ to $150 \pm 20 / 87 \pm 9 \mathrm{~mm} \mathrm{Hg}(P<0.01)$ at steady state and to $153 \pm 17 / 88 \pm 9 \mathrm{~mm} \mathrm{Hg}$ (not significant) after the drug holiday. The between-group difference was highly significant for SBP at steady state $(P<0.001)$ and after the drug holiday $(P<0.01)$, whereas it only reached statistical significance during therapy for DBP $(P<0.01)$.

\section{Safety and tolerability}

Consistent with extensive clinical findings regarding amlodipine and losartan, both drugs were well tolerated. Overall, 15\% of patients in the amlodipine group and $13 \%$ of patients in the losartan group experienced at least one adverse event, with edema (7\%) and headache (5\%) being the most commonly reported events in each group, respectively. Three patients in the amlodipine group (one with vertigo, one with a perforated stomach ulcer and one with edema and dizziness) and one patient in the losartan group (headache and vertigo) had an adverse event that led to the discontinuation of study medication.

\section{DISCUSSION}

In this study, for patients older than 65 years with mild-to-moderate hypertension, amlodipine appeared to lower blood pressure more effectively than losartan when assessed by ambulatory blood pressure measurements. Although both drugs lowered blood pressure, the effect was significantly greater in patients treated with amlodipine both 

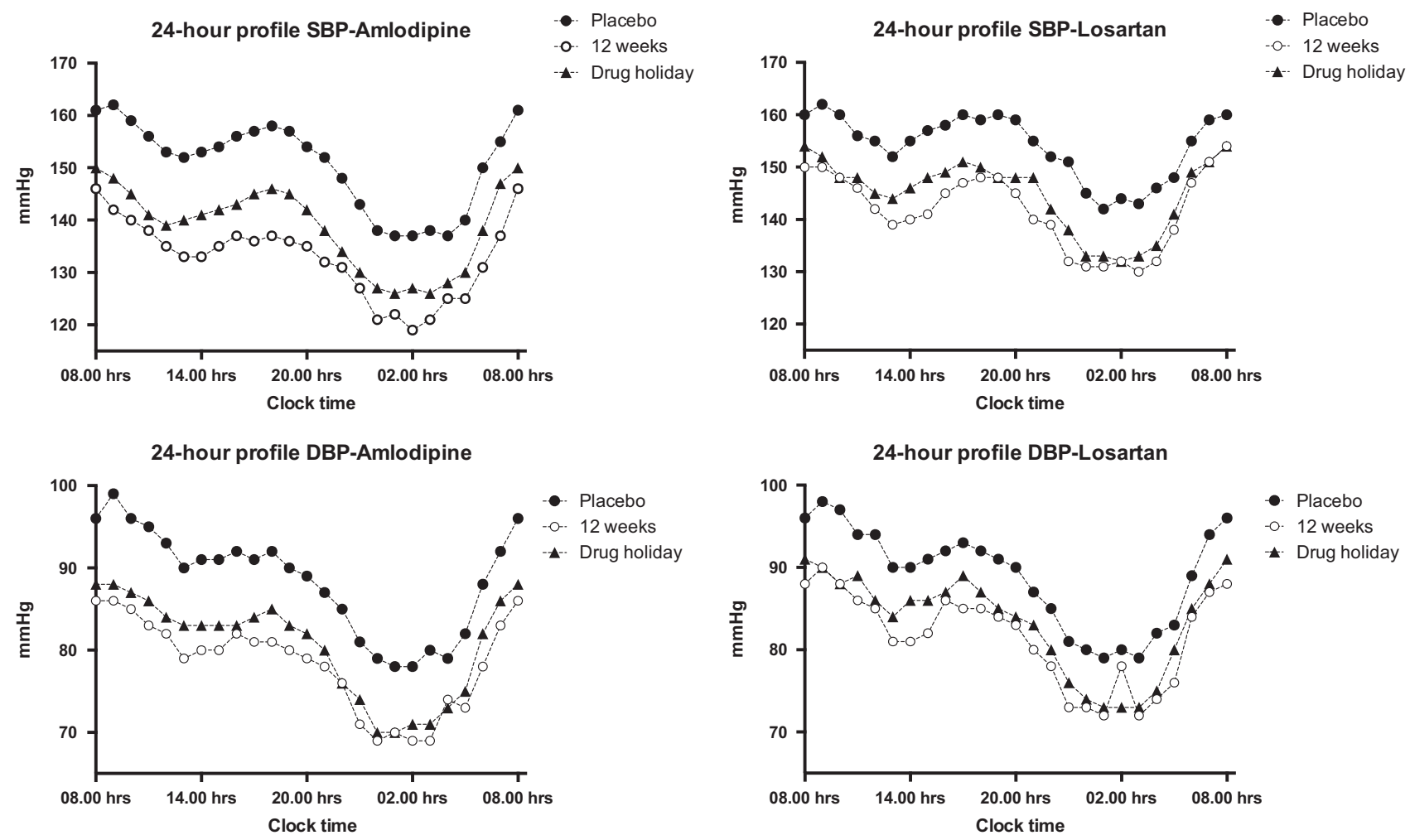

Figure 2 The 24-h blood pressure profiles at baseline, during treatment and after two missed doses.

during treatment and after 2 days of missed doses. This difference was observed not only for 24-h blood pressure but also for daytime and nighttime pressures separately. These results were further corroborated by the office BP data, which also suggested a greater effect of amlodipine, at least on SBP.

The main purpose of this study was to compare the effect of the withdrawal of amlodipine and losartan on blood pressure profiles after a 2-day drug holiday in older patients with hypertension. The drug holiday was based on the so-called 'placebo-substitution-for-active' approach and used as a surrogate for less than-optimal adherence (that is, missed doses). It allowed for a comparison of the therapeutic coverage of the two drugs used in this study. The ability of a drug to maintain its action in the face of occasional lapses in dosing is referred to as 'forgiveness', which is the difference between the duration of the beneficial action of a drug after it has been stopped and the prescribed dosing interval. ${ }^{6}$ A longer forgiveness may be related to an extended plasma half-life of the drug or to a prolonged pharmacodynamic effect or both.

Amlodipine is a long-acting dihydropyridine calcium antagonist with a half-life of $40-50$ h. ${ }^{7,8}$ Previous studies have shown that the interruption of chronic treatment with amlodipine for 2 days results in only a minor decrease in its antihypertensive effect. ${ }^{9,10}$ The plasma half-life of the active metabolite of losartan, on the other hand, is much shorter, ${ }^{11}$ and one would thus expect less forgiveness with losartan. In reality, however, the issue is a bit more complicated. In this study, for instance, the rise in SBP during the drug holiday was significantly greater in patients who had been treated with amlodipine than in those who had received losartan. With respect to changes in DBP, the two groups did not differ at all from each other. It is only because amlodipine had produced a greater decrease in blood pressure than losartan at the end of the active treatment period that the amlodipine group ended up with significantly lower pressure after the interruption of therapy. Thus, the implications for cessation of treatment cannot be predicted simply on the basis of alleged pharmacokinetic profiles. It may be, however, that the rise in post-treatment blood pressure is greater when it starts from a lower level during treatment. Our data would certainly be consistent with that view, but more extensive studies are needed to support or disprove such a hypothesis.

The 24-h blood pressure profile, including the degree of dipping and the early morning rise, was well-maintained and did not differ between the two groups, neither at the end of the steady state nor at the end of drug holiday. Thus, stopping the medication had no influence whatsoever on the diurnal variations in pressure but solely on the peak of blood pressure.

Only a few studies have addressed the comparative efficacy of antihypertensive agents after missed doses in an appropriate manner, that is, using 24-h blood pressure monitoring. ${ }^{4}$ These studies have yielded variable results, and from the data, it is difficult to predict what will happen when treatment with a certain agent is suddenly stopped. One of the trials had a similar design as ours and reported results that are comparable to ours, albeit the magnitude of the rise in SBP after drug withdrawal was similar for amlodipine and losartan. ${ }^{12}$ However, that study was conducted in a younger population with a lower baseline blood pressure, and it did not focus specifically on older individuals. Still, both studies demonstrate that amlodipine as well as losartan still significantly reduce blood pressure after a 48-h drug holiday. Whether this finding has any clinical relevance remains to be demonstrated. Although we would like to believe that the sustained action of any antihypertensive agent after its withdrawal is beneficial, there is no proof that this is the case.

There are, of course, a few limitations to this study. First, we did not measure the plasma levels of the active drugs. However, it was not our intention to do a pharmacokinetic study but rather to explore the 
outcomes of a sudden cessation of treatment with respect to everyday clinical practice. Second, we limited our monitoring to only $48 \mathrm{~h}$. Therefore, we do not know to what extent prolonged interruption of treatment will affect blood pressure responses. Finally, patients knew that they were receiving placebo tablets at the end of the study. Although they did not know what treatment they were on (amlodipine or losartan), this knowledge could still have influenced individual fears or expectations regarding a rise in their blood pressure. On the other hand, one would anticipate any such reactions to be equally distributed among the two groups.

In conclusion, the results of this study in patients aged older than 65 years show that, in comparison with losartan, amlodipine is significantly more effective in lowering blood pressure during therapy, as well as after two missed doses. Although the absolute increase in blood pressure during the drug holiday was greater in the amlodipinetreated group, patients from this group seem to be better protected against the effects of incidental non-compliance because of the greater efficacy of amlodipine compared with losartan. This finding may have relevance for guidelines regarding the treatment of hypertension in older individuals.

\section{CONFLICT OF INTEREST}

The authors declare no conflict of interest.

\section{ACKNOWLEDGEMENTS}

The following investigators participated in the multicenter study group: Belgium: H Bekkers (Deurne), Jean-Paul Degaute (Bruxelles), Robert Fagard (Leuven), Jean-Paul Meurant (La Louvière), Paul Remont (Manage) and Luc van Parys (Lembeek); Czech Republic: Pavel Havranek (Ceske Budèjovice), Jan Pavlas (Ostrava-Kuncice), Rudolf Ramaisl (Prague) and Jan Radotinsky (Ceska Lipa); Hungary: Gábor Nagy (Balatonfüred), György Sallai (Budapest) and Zoltán Kovács (Körösladány); The Netherlands: Frans de Heer (Sittard), Abraham Kroon (Maastricht), Peter de Leeuw (Maastricht) and Frans Lustermans (Heerlen); Poland: Zbigniew Gaciong (Warsaw), Joanna Niegowska (Warsaw) and Andrzej Więcek (Katowice); Russia: Yuri Karpov (Moscow), Leonid Lazebnik (Moscow) and Boris Sidorenko (Moscow); Slovak Republic:
Rastislav Dzúrik (Bratislava) and Zoltan Mikes (Bratislava). This research was supported by a grant from Pfizer, New York, USA. The authors received a research grant related to this work.

1 Vrijens B, Vincze G, Kristanto P, Urquhart J, Burnier M. Adherence to prescribed antihypertensive drug treatments: longitudinal study of electronically compiled dosing histories. BMJ 2008; 336: 1114-1117.

2 Oh SW, Han SY, Han KH, Cha RH, Kim S, Yoon SA, Rhu DR, Oh J, Lee EY, Kim DK, Kim YS, Investigators AP. Morning hypertension and night non-dipping in patients with diabetes and chronic kidney disease. Hypertens Res 2015; 38: 889-894.

3 Hermida RC, Ayala DE, Smolensky MH, Fernandez JR, Mojon A, Portaluppi F. Chronotherapy with conventional blood pressure medications improves management of hypertension and reduces cardiovascular and stroke risks. Hypertens Res 2016; 39: 277-292.

4 Dusing R, Brunel P, Baek I, Baschiera F. Sustained blood pressure-lowering effect of aliskiren compared with telmisartan after a single missed dose. J Clin Hypertens (Greenwich) 2013; 15: 41-47.

5 Blood Pressure Lowering Treatment Trialists C, Turnbull F, Neal B, Ninomiya T, Algert C, Arima H, Barzi F, Bulpitt C, Chalmers J, Fagard R, Gleason A, Heritier S, Li N, Perkovic V, Woodward M, MacMahon S. Effects of different regimens to lower blood pressure on major cardiovascular events in older and younger adults: meta-analysis of randomised trials. BMJ 2008; 336: 1121-1123.

6 Osterberg LG, Urquhart J, Blaschke TF. Understanding forgiveness: minding and mining the gaps between pharmacokinetics and therapeutics. Clin Pharmacol Ther 2010; 88: 457-459.

7 Elliott HL, Green ST, Vincent J, Meredith PA. An assessment of the pharmacokinetics and pharmacodynamics of single doses of amlodipine in elderly normotensives. Pharmacol Res 1992; 26: 33-39.

8 Meredith PA, Elliott HL. Clinical pharmacokinetics of amlodipine. Clin Pharmacokinet 1992; 22: 22-31.

9 Leenen FH, Fourney A, Notman G, Tanner J. Persistence of anti-hypertensive effect after 'missed doses' of calcium antagonist with long (amlodipine) vs short (diltiazem) elimination half-life. Br J Clin Pharmacol 1996; 41: 83-88.

10 Biston P, Melot C, Degaute JP, Clement D, Quoidbach A. Prolonged antihypertensive effect of amlodipine: a prospective double- blind randomized study. Blood Press 1999; 8: 43-48.

11 Lo MW, Goldberg MR, McCrea JB, Lu H, Furtek Cl, Bjornsson TD. Pharmacokinetics of losartan, an angiotensin II receptor antagonist, and its active metabolite EXP3174 in humans. Clin Pharmacol Ther 1995; 58: 641-649.

12 Ribeiro AB, Mion D Jr, Marin MJ, Majul C, Botero R, Lopez R, Gonzalez S, Izurieta H, Francischetti EA, Latin American Hypertension Study G. Antihypertensive efficacy of amlodipine and losartan after two 'missed' doses in patients with mild to moderate essential hypertension. J Int Med Res 2007; 35: 762-772. 